\title{
Dynamics Modeling and Modal Analysis of Machine Tool Considering Joints Parameters
}

\author{
Yongyi Liao $^{1,2}$, Baiyu Liao ${ }^{1}$ \\ ${ }^{1}$ Key Laboratory of Vibration and Noise under Ministry of Education of Yunnan Province, Kunming 650500, China. \\ ${ }^{2}$ Adult Education College, Kunming University of Science and Technology, Kunming 650051, China. Email: \\ yongyiliao@163.com
}

\begin{abstract}
Based on analysis of joint dynamic characteristics to obtain dynamic values of combined surface incorporating joint dynamic data, a method for dynamics modeling of machine tool considering joint dynamic characteristics is developed and analyzed. The machine tool is simplified and modeled by selecting the motion coordinates of each component in accordance with the structure characteristics and the vibration displacement for each component in exciting test. According to the way and condition of the joints, the equivalent dynamic parameters of each joint are determined by applying the general joint surface dynamic data. Calculation methods of dynamic parameters for some typical joints in machine tool structures are analyzed and described. Taking a horizontal milling machine as an example, the machine is simplified into a dynamic model with 21 degrees of freedom, the calculated results of dynamic characteristics correspond to that of exciting test and modal analysis. The modeling method is effective and applicable in machine tool design and structure improvement.
\end{abstract}

Keywords: Machine tool, Modeling, Dynamic model, Joints parameters, Dynamic characteristics

\section{Introduction}

To establish the dynamic model that simulates the machine tool structure is the requirement to analyze the dynamic characteristics and realize optimum design. For complex machine tool structure, it is still difficult to obtain the dynamic model in physical coordinates due to the existence of various joints [1-5]. By simplifying machine tool to a certain extent in different ways, a lumped parameter model, a beam distributed model or a finite element model is established correspondingly [6,7], the modeling is limited by the difficult to identify the joints parameters, and the modeling accuracy is not up to the requirement of dynamic optimization[ 8,9$]$. Based on the theory of experimental modal analysis and using experimental data, the modal model for machine tool is established [10,11]. With the development of experimental modal analysis technology, although it is convenient to determine the modal mass, modal stiffness and modal damping ration of each modal of machine tool, as viewed from design improvement and optimum design, the obtained modal model could not related directly to the specific design improvement and optimum design[12,13], only some approximately concussions can be obtained. On the contrary, the dynamic model in physical coordinates is convenient and direct in point of this.

Based on analysis of joint dynamic characteristics, a method of modeling the dynamic model in physical coordinates of machine tool considering joint dynamic characteristics is explored. The motion coordinates for each component are decided according to the characteristics of structure and displacement for each component in exciting test of machine tool. The dynamics equations of machine tool are obtained by the second type of Lagrange equations. Dynamic parameters for some typical joints in machine tool structures are analyzed and the equivalent parameters of each joint are determined by applying the general joint surface dynamic data.

\section{Dynamic model of horizontal milling machine}

The horizontal milling machine is a middle-sized product with broad versatility, shown in Fig. 1. In accordance with the structural features and distributions of this machine, it is divided into eight parts: (1) Bed (including bottom base); (2) Horizontal spindle body (including main motor, motor stand and vertical spindle body); (3) Crossbeam; (4) Hanger; (5) Horizontal cutter arbor; (6) Horizontal table; (7) Vertical table; (8) Compound slide.

Compound slide fits bed with rectangular slideway. Between horizontal spindle body and bed, crossbeam and horizontal spindle body, hanger and crossbeam as well as vertical table and compound slide are all fitted each other with dovetail slideway. Horizontal table and vertical table are joined by four bolts.
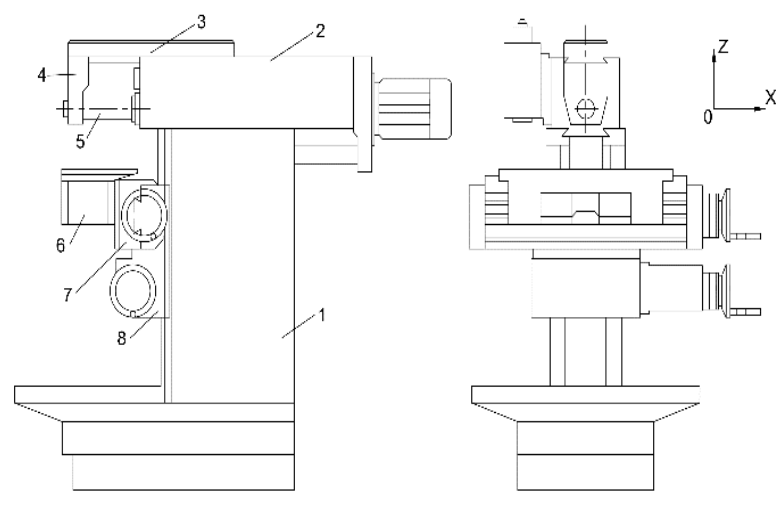

Fig. 1 Structure diagram of horizontal milling machine

In accordance with the characteristics of displacement in exciting test of the machine tool, the machine is represented by a dynamic model involving lumped and distributed masses with 21 degrees of freedom. By applying the second type of Lagrange equations[14], the differential equations of machine tool are obtained as follows 


$$
\frac{d}{d t}\left[\frac{\partial T}{\partial \dot{q}_{j}}\right]-\frac{\partial T}{\partial q_{j}}+\frac{\partial U}{\partial q_{j}}+\frac{\partial D}{\partial \dot{q}_{j}}=Q_{j} \quad j=1,2, \cdots, 21
$$

Where: $T$...the total kinetic energy of the system, $q_{j}$ ...the generalized coordinate of the system, $U$...the total potential energy of the system, $D$...the Rayleigh energy dissipation function, and $Q_{j}$...the exciting force. According to the dynamic model, $T, U$ and $D$ of the structure are calculated, substitute $T, D, U$ in equation (1), then we obtain

$$
\boldsymbol{M}_{21 \times 21} \ddot{\boldsymbol{q}}_{21 \times 1}+\boldsymbol{C}_{21 \times 21} \dot{\boldsymbol{q}}_{21 \times 1}+\boldsymbol{K}_{21 \times 21} \boldsymbol{q}_{21 \times 1}=\boldsymbol{F}(t)_{21 \times 1}
$$

Where, $\boldsymbol{M}$ denotes the mass matrix, $\boldsymbol{C}$ is damping matrix and $K_{K}$ is the stiffness matrix, while ${ }_{q}$ is the column matrix of generalized coordinates and $\boldsymbol{F}(t)$ is the column matrix of exciting forces.

Masses of each component involved in the model are found by weighing actual structures. By the principle of compound pendulum, moments of inertia are determined by measuring the oscillation frequency in gravity field, while neglecting the effect of friction moment on the edge of the blade bearing.

\section{Analysis of joints dynamic characteristics}

The dynamic characteristics of the joint have a significant influence on the dynamic performance of machine tool $[15,16]$. The identification of the dynamic parameters of joint is the basis and premise for the accurate establishing of the whole machine tool dynamic model. Based on analysis of characteristics of joints, by applying the general joint surface dynamic data $k_{i}\left(P_{n}\right)$ and $c_{i}\left(P_{n}\right)(i=$ $1,2)[3,17]$, the equivalent spring stiffness and viscous damping coefficients of each joint in the model are analyzed. $k_{i}\left(P_{n}\right)$ and $c_{i}\left(P_{n}\right)(i=1,2)$ denote equivalent spring stiffness and damping coefficient values per unit area, which are obtained by experiment and computer simulation. They are functions of contact pressure. Subscripts $(i=1,2)$ represent shear direction and normal direction respectively. It is confirmed that the joint dynamics data $k_{i}\left(P_{n}\right)$ and $c_{i}\left(P_{n}\right)(i=1,2)$, which depend on the mean contact pressure, can be applied satisfactorily to general joints which have the same contact surface properties but differ in shape and contact area.

There are various joints in machine tool structure, with fixed and sliding of joint ways, as well as with surface contact, rectangular slideway and dovetail slideway of joint patterns, and with different forces state. In order to identify the dynamic parameters of these joints by using general joint surface dynamic data, the forces on contact surface should be analyzed for different joints.

For a contact surface, the forms of dynamic force supported on contact surface are determined by modal shapes. The contact surface can be supported six different forms of dynamic forces, which are generalized forces over six coordinates as shown in Fig. 2. These dynamic forces are normal force $F_{y}$ along axis y and shearing force $F_{x}, F_{z}$ along axis $\mathrm{x}$ and $\mathrm{z}$, bending moment $M_{\theta x}, M_{\theta z}$ around axes $\mathrm{x}$ and $\mathrm{z}$, and shear bending moment $M_{\theta y}$ around axis $\mathrm{y}$. The contact surface may be supported all of them or any of these forces. Integral over area replaced by the point $G$, the equivalent spring stiffness and damping coefficients at point $G$ are obtained as indicated in the following equations:

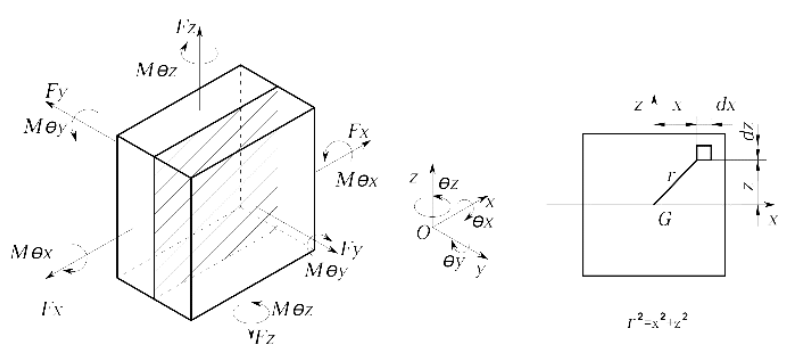

Fig. 2 Diagrammatic sketch of the forces on contact surface

$$
\left.\begin{array}{l}
K_{x}=\iint k_{1}\left(P_{n}\right) \mathrm{d} x \mathrm{~d} z=K_{z} \\
K_{y}=\iint k_{2}\left(P_{n}\right) \mathrm{d} x \mathrm{~d} z \\
K_{\theta y}=\iint\left(y^{2}+z^{2}\right) k_{1}\left(P_{n}\right) \mathrm{d} x \mathrm{~d} z \\
K_{\theta x}=\iint z^{2} k_{2}\left(P_{n}\right) \mathrm{d} x \mathrm{~d} z \\
K_{\theta z}=\iint y^{2} k_{2}\left(P_{n}\right) \mathrm{d} x \mathrm{~d} z \\
C_{x}=\iint c_{1}\left(P_{n}\right) \mathrm{d} x \mathrm{~d} z=c_{z} \\
C_{y}=\iint c_{2}\left(P_{n}\right) \mathrm{d} x \mathrm{~d} z \\
C_{\theta y}=\iint\left(y^{2}+z^{2}\right) c_{1}\left(P_{n}\right) \mathrm{d} x \mathrm{~d} z \\
C_{\theta x}=\iint z^{2} c_{2}\left(P_{n}\right) \mathrm{d} x \mathrm{~d} z \\
C_{\theta z}=\iint y^{2} c_{2}\left(P_{n}\right) \mathrm{d} x \mathrm{~d} z
\end{array}\right\}
$$

Based on the equation (3), for dovetail slideway joint, shown in Fig. 3, the equivalent spring stiffness at point $G$ can be derived by calculating the spring stiffness around point $\mathrm{G}$ as follows

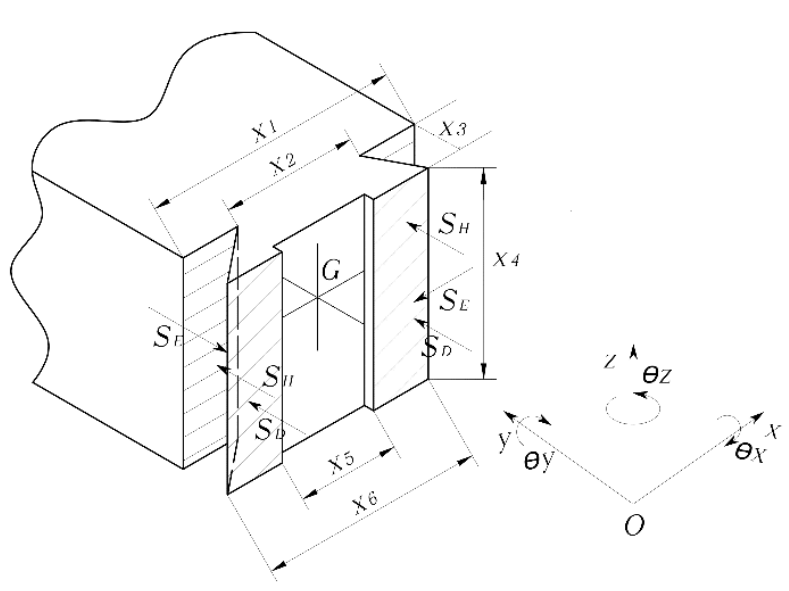

Fig. 3 Dovetail slideway joint 


$$
\left.\begin{array}{l}
K_{x}=2\left(K_{D x}+K_{H x}+K_{E x} \cos \theta+K_{E y} \sin \theta\right) \\
K_{y}=2\left(K_{D y}+K_{H y}+K_{E x} \sin \theta+K_{E y} \cos \theta\right) \\
K_{z}=2\left(K_{D z}+K_{H z}+K_{E z}\right) \\
K_{\theta x}=2\left[K_{D \theta x}+K_{H \theta x}+K_{E \theta x} \cos \theta+K_{E \theta y} \sin \theta+\frac{x_{3}^{2}}{4}\left(K_{H z}+K_{D z}\right)\right] \\
K_{\theta y}=2\left[K_{D \theta y}+K_{H \theta y}+K_{E \theta x} \sin \theta+K_{E \theta y} \cos \theta+\frac{\left(x_{1}+x_{2}\right)^{2}}{16} K_{H z}+\frac{\left(x_{5}+x_{6}\right)^{2}}{16} K_{D z}+\frac{\left(x_{6}+x_{2}\right)^{2}}{16} K_{E z}\right] \\
K_{\theta z}=2\left[K_{D \theta z}+K_{H \theta z}+\frac{\left(x_{1}+x_{2}\right)^{2}}{16} K_{H y}+\frac{\left(x_{5}+x_{6}\right)^{2}}{16} K_{D y}+K_{E \theta z}+\frac{\left(x_{6}+x_{2}\right)^{2}}{16}\left(K_{E x} \sin \theta+K_{E y} \cos \theta\right)+\frac{x_{3}^{2}}{4}\left(K_{H x}+K_{D x}\right)\right]
\end{array}\right\}
$$

For rectangular slideway joint shown in Fig. 4, the equivalent spring stiffness at point $G$ can be derived as

$$
\left.\begin{array}{l}
K_{x}=2\left(K_{D x}+K_{H x}+K_{E y}+K_{T y}\right) \\
K_{y}=2\left(K_{D y}+K_{H y}+K_{E x}+K_{T x}\right) \\
K_{z}=2\left(K_{D z}+K_{H z}+K_{E z}+K_{T z}\right) \\
K_{\theta x}=2\left[K_{D \theta x}+K_{H \theta x}+K_{E \theta y}+K_{T \theta y}+\frac{x_{3}^{2}}{4}\left(K_{H z}+K_{D z}\right)\right] \\
K_{\theta y}=2\left[K_{D \theta y}+K_{H \theta y}+K_{E \theta x}+K_{T \theta x}+\frac{\left(x_{1}+x_{5}\right)^{2}}{16} K_{H z}+\frac{\left(x_{1}+x_{2}\right)^{2}}{16} K_{D z}+\frac{x_{6}^{2}}{4} K_{T z}+\frac{x_{1}^{2}}{4} K_{E z}\right] \\
K_{\theta z}=2\left[K_{D \theta z}+K_{H \theta z}+K_{E \theta z}+K_{T \theta z}+\frac{\left(x_{1}+x_{5}\right)^{2}}{16} K_{H y}+\frac{\left(x_{1}+x_{2}\right)^{2}}{16} K_{D y}+\frac{x_{3}^{2}}{4}\left(K_{H x}+K_{D x}\right)+\frac{x_{1}^{2}}{4} K_{E x}+\frac{x_{6}^{2}}{4} K_{T x}\right]
\end{array}\right\}
$$

Similarly, the equations for calculating the equivalent

\begin{tabular}{|c|c|c|c|c|c|}
\hline Joint & Stiffn & $(\mathrm{N} / \mathrm{m} ; \mathrm{N} \cdot \mathrm{m} / \mathrm{rad})$ & Joint & Stif & $/ \mathrm{m} ; \mathrm{N} \cdot \mathrm{m} / \mathrm{rad})$ \\
\hline \multirow{3}{*}{$\begin{array}{l}\text { Joint of bed and horizon- } \\
\text { tal spindle body }\end{array}$} & $K_{x}^{(1)}$ & $7.642 \times 10^{8}$ & \multirow{2}{*}{ Crossbeam and hanger } & $K_{\theta x}^{(3)}$ & $7.366 \times 10^{6}$ \\
\hline & $K_{\theta x}^{(1)}$ & $3.629 \times 10^{7}$ & & $K_{\theta z}^{(3)}$ & $1.164 \times 10^{7}$ \\
\hline & $K_{\theta z}^{(1)}$ & $5.473 \times 10^{7}$ & \multirow{2}{*}{$\begin{array}{l}\text { Horizontal table and } \\
\text { vertical table }\end{array}$} & $K_{x}^{(}$ & $2.512 \times 10^{9}$ \\
\hline Bed and compound slide & $K_{x}^{(8)}$ & $3.829 \times 10^{8}$ & & $K_{z}^{(6)}$ & $2.512 \times 10^{9}$ \\
\hline \multirow{3}{*}{$\begin{array}{l}\text { Horizontal spindle body } \\
\text { and crossbeam }\end{array}$} & $K_{x}^{(2)}$ & $2.012 \times 10^{8}$ & \multirow{3}{*}{$\begin{array}{l}\text { Vertical table and com- } \\
\text { pound slide }\end{array}$} & $K_{x}^{(\vartheta)}$ & $7.218 \times 10^{5}$ \\
\hline & $K_{\theta x}^{(2)}$ & $6.725 \times 10^{6}$ & & $K_{\theta x}^{\curvearrowright}$ & $4.538 \times 10^{7}$ \\
\hline & $K_{\theta z}^{(2)}$ & $1.054 \times 10^{7}$ & & $K_{\theta_{v}}^{(}$ & $4.341 \times 10^{7}$ \\
\hline
\end{tabular}
damping coefficients are derived. In the first subscripts D, H, E, T correspond to the joint surface $S_{D}, S_{H}, S_{E}$ and $S_{T}$, while the second subscripts $x, y, z, \theta_{x}, \theta_{y}, \theta_{z}$ correspond to the directions of six coordinates respectively.

By applying above equations, the equivalent spring stiffness coefficients in the model are calculated, and the results for equivalent spring stiffness of joints are displayed in Table 1.

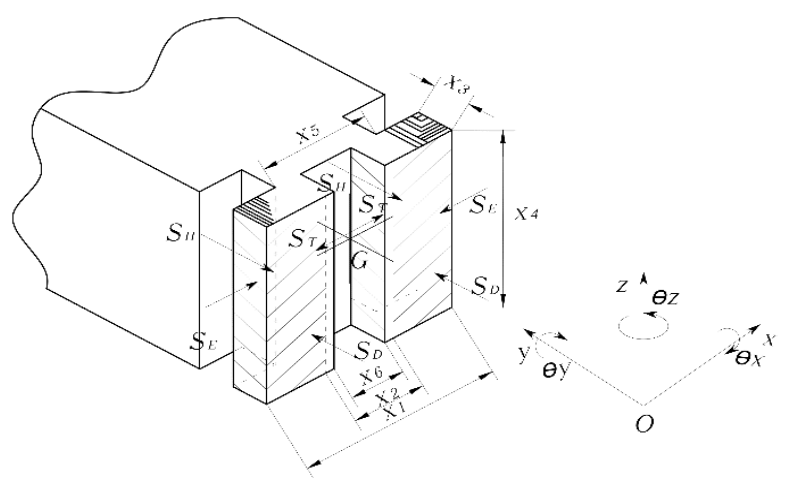

Fig. 4 Rectangular slideway joint

Tab. 1 The values of equivalent stiffness of each joint

Note: In the table the unit of line stiffness is $\mathrm{N} / \mathrm{m}$; and angular stiffness is $\mathrm{N} \cdot \mathrm{m} / \mathrm{rad}$.

\section{Dynamic characteristics computation and modal analysis}

Solving the eigenvalue problem of equation (2), the characteristic equation is as follows

$$
\boldsymbol{K} \phi_{i}=\omega_{i}^{2} \boldsymbol{M} \phi_{i}
$$

Where $\phi$ is r-order eigenvector, the natural frequen$\operatorname{cies} \omega_{n 1}, \omega_{n 2}, \cdots, \omega_{n 21}$ and vibration vectors $\boldsymbol{A}^{1}, \boldsymbol{A}^{2}, \cdots$ , $A^{21}$ of the structural system can be obtained respectively by solving above equation.

The actual cutting conditions are simulated approximately by the relative exciting shown in the Fig. 5 . In the case of relative exciting between cutter and workpiece, a pair of equal and opposite force $-F_{e} e^{i \omega t}$ at the point of horizontal cutter arbor and $F_{e} e^{i \omega t}$ at the point of horizontal table are applied along the direction of $\alpha$ angle, $-F_{e} e^{i \omega t}$ and $F_{e} e^{i \omega t}$ are decomposed into a pair of orthogonal forces along the axis $\mathrm{x}$ and $\mathrm{z}$ respectively. Thus, the exciting force column matrix can be expressed as 


$$
\boldsymbol{F}(t)=\left[00000000000,-F_{e 12 x} e^{i \omega t}, F_{e 13 z} e^{i \omega t}, 00, F_{e 16 x} e^{i \omega t},-F_{e 17 z} e^{i \omega t}, 0000\right]^{\mathrm{T}}=\boldsymbol{F} e^{i \omega t}
$$

Denoting tool-workpiece relative displacement in the direction normal to machined surface by $X_{c}$, in accordance with theory of modal analysis, the compliance of

$$
W_{c}=\frac{X_{c}}{F_{e}}=\sum_{r=1}^{21} \frac{\left[\left(A_{16}^{(r)}-A_{12}^{(r)}\right) \cos \alpha+\left(A_{13}^{(r)}-A_{17}^{(r)}\right) \sin \alpha\right]\left(A_{13}^{(r)}-A_{17}^{(r)}\right)}{K_{r}\left[1-\left(\frac{\omega}{\omega_{n r}}\right)^{2}+i \cdot 2 \xi_{r}\left(\frac{\omega}{\omega_{n r}}\right)\right]}
$$

Where: $A_{12}^{(r)}, A_{13}^{(r)}, A_{16}^{(r)}, A_{17}^{(r)} \ldots$ the r-order modal vectors corresponding to the generalized coordinate $q_{12}$, $q_{13}, q_{16}, q_{17} ; K_{r} \ldots$ the r-order modal stiffness; $\xi_{\text {. }} .$. the r-order modal damping ratio; $\omega, \omega_{n r} \ldots$ exciting frequency and the r-order natural frequency; $\alpha$...the included angle between exciting force $F_{e} e^{i \omega t}$ and horizontal direction.

The modal damping ratio $\xi_{r}$ used in calculation is obtained by analyzing the machine tool relative pseudo-random exciting test data processing by analyzer 7T17S. Table 2 compares the modal frequencies in relative pseudorandom exciting with computed natural frequencies. Fig. 6 shows the vibration modal shape of the main modes of $151.4 \mathrm{~Hz}$ and $187.7 \mathrm{~Hz}$. Fig. 7 compares the computed frequency response at cutting point with that of exciting test. The dotted lines indicate the computed results, while the solid line is the relative harmonic exciting results. The correspondence between the calculated results and the measured results indicates that the dynamic analytic model established is in line with the experimental situation, cutter-workpiece at cutting point can be derived as follows

\begin{tabular}{|c|c|c|c|c|c|c|c|}
\hline \multirow{2}{*}{$\begin{array}{l}\text { Modal } \\
\text { order }\end{array}$} & \multirow{2}{*}{$\begin{array}{l}\begin{array}{l}\text { Computed re- } \\
\text { sults }\end{array} \\
\begin{array}{l}\text { Natural fre- } \\
\text { quency }(\mathrm{Hz})\end{array}\end{array}$} & \multicolumn{2}{|c|}{ Experimental value } & \multirow{2}{*}{$\begin{array}{l}\text { Modal } \\
\text { order }\end{array}$} & \multirow{2}{*}{$\begin{array}{l}\text { Computed re- } \\
\text { sults } \\
\text { Natural } \\
\text { frequency }(\mathrm{Hz})\end{array}$} & \multicolumn{2}{|c|}{ Experimental value } \\
\hline & & $\begin{array}{l}\text { Modal fre- } \\
\text { quency }(\mathrm{Hz})\end{array}$ & $\begin{array}{l}\text { Modal } \\
\text { damping } \\
\text { ratio }\end{array}$ & & & $\begin{array}{l}\text { Modal fre- } \\
\text { quency }(\mathrm{Hz})\end{array}$ & $\begin{array}{l}\text { Modal } \\
\text { damping } \\
\text { ratio }\end{array}$ \\
\hline 1 & 17.586 & 17.678 & 0.139 & 9 & 301.210 & 300.094 & 0.0250 \\
\hline 2 & 39.154 & $\longrightarrow$ & $\longrightarrow$ & 10 & 365.411 & 372.533 & 0.0134 \\
\hline 3 & 64.301 & 65.048 & 0.0384 & 11 & 410.936 & 410.122 & 0.0244 \\
\hline 4 & 109.278 & 123.908 & 0.0503 & 12 & 460.676 & - & - \\
\hline 5 & 156.286 & 151.379 & 0.0412 & 13 & 470.350 & $\longrightarrow$ & $\longrightarrow$ \\
\hline 6 & 192.470 & 187.650 & 0.0399 & 14 & 491.494 & 491.328 & 0.0178 \\
\hline 7 & 266.715 & - & - & 15 & 526.796 & 533.787 & 0.0117 \\
\hline 8 & 279.518 & - & 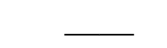 & 16 & 1146.472 & 990.003 & 0.00253 \\
\hline
\end{tabular}

Tab. 2 Comparison between natural frequencies and modal frequencies

and the model well simulates the dynamic characteristics of machine tool.

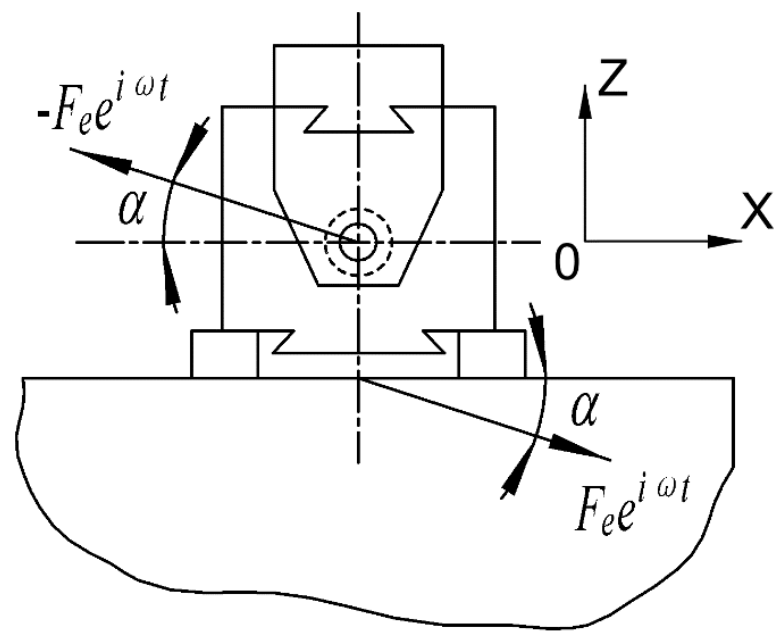

Fig. 5 Diagram of exciting force 


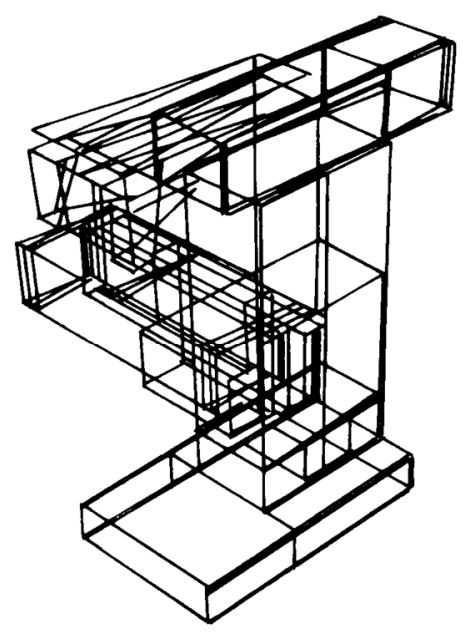

X Direction $151.4 \mathrm{~Hz}$

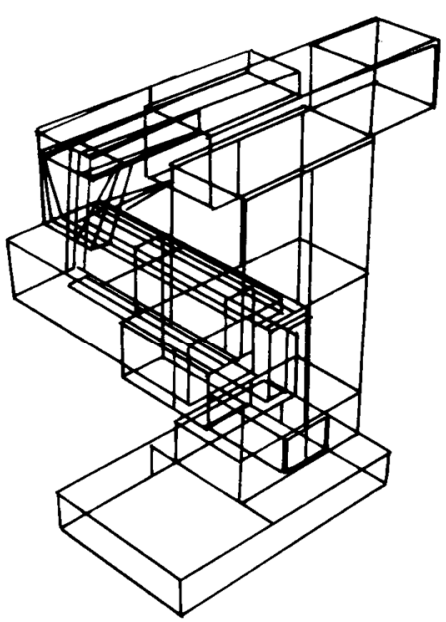

X Direction $187.7 \mathrm{~Hz}$

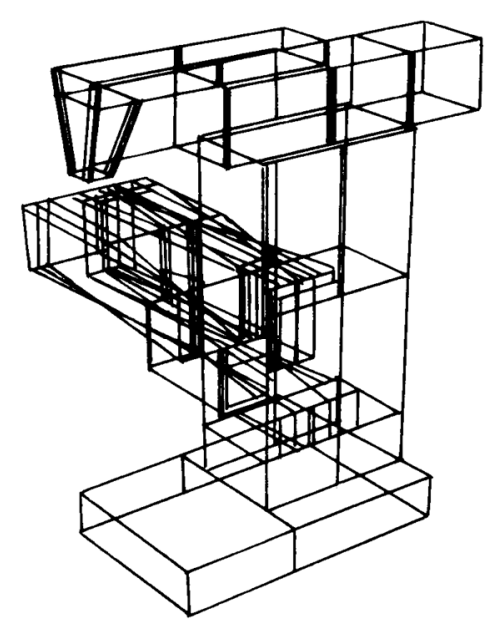

Y Direction $151.4 \mathrm{~Hz}$

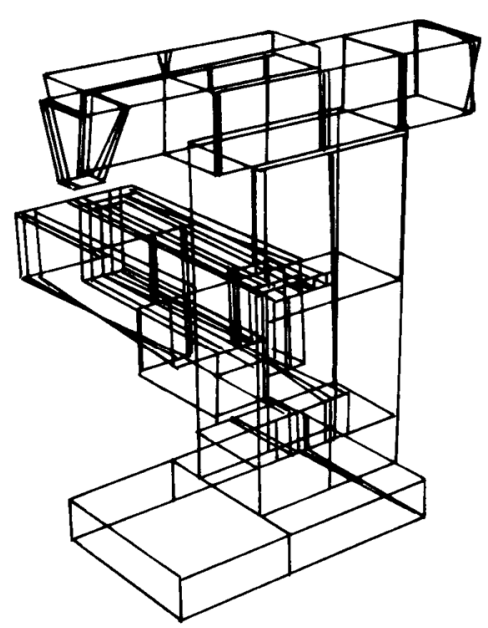

Y Direction $187.7 \mathrm{~Hz}$

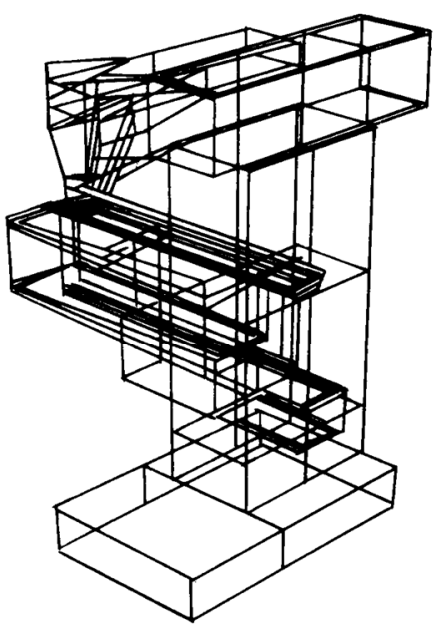

Z Direction $152.7 \mathrm{~Hz}$

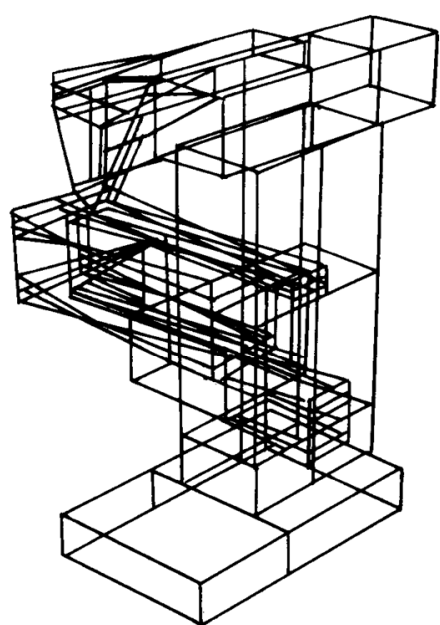

Z Direction $202.9 \mathrm{~Hz}$

Fig. 6 Vibration modal shape of machine tool

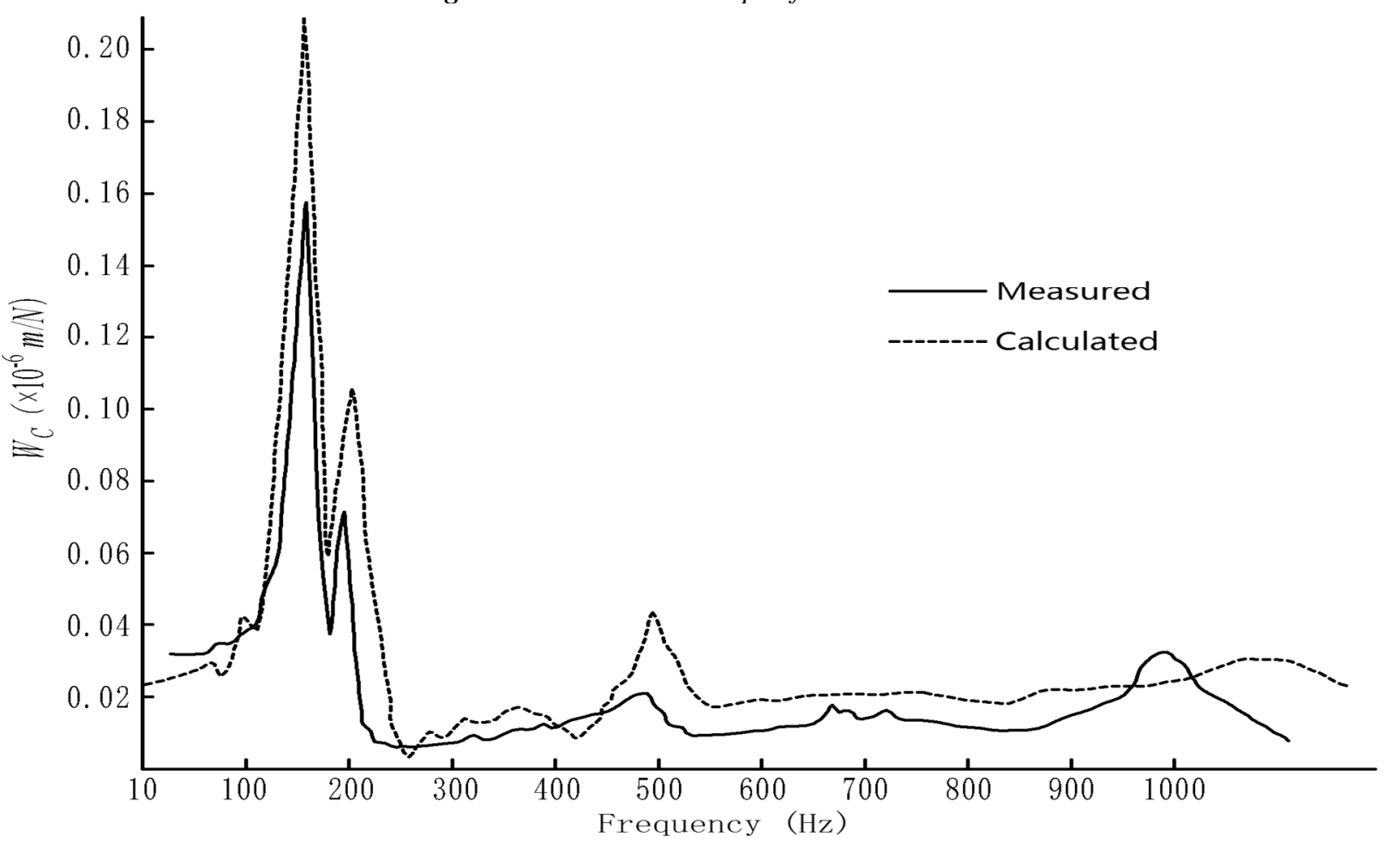

Fig. 7 Computed and measured results of the relative compliance 


\section{Conclusions}

1. The method to establish the dynamic model of machine tool structure considering joint dynamic characteristics is feasible and applicable to engineering.

2. The dynamic model established well simulates the dynamic characteristics of the actual structure, the computed results agree with that of exciting test and modal analysis.

3. The Lagrangian equation based on the energy principle is used to establish the motion equation of machine tool structure, which is convenient to calculate the energy distribution and proportion of each component in the system, and provides the basis for the subsequent dynamic optimization design and structural improvement.

\section{Acknowledgements}

This work was supported by National Natural Science Foundation of China grants program (51465021) and Yunnan province science and technology plan project (S2016DC069).

\section{References}

[1] DONG G. H., YIN Q., YIN G. F., et al. (2016). Research on dynamics modeling and identification of machine tool joints. In: Journal of Mechanical Engineering, Vol. 52, No. 5, pp. 162-168.

[2] DENG C. Y., YIN G. F., FANG H., et al. (2015). Optimal configuration of dynamic stiffness of machine tool joints based on orthogonal experiment. In: Journal of Mechanical Engineering, Vol. 51, No. 19, pp. 146-153.

[3] GUO T. N., YU X. L., LI F. P., et al. (2013). Modeling study of the cnc heavy-duty gantry machine coupling with the characteristics of the joint surfaces. In: Journal of Beijing University of Technology, Vol. 39, No. 3, pp. 331-338.

[4] WANG Z. (2018). Research on the design of a mill-turn center. In: Manufacturing Technology, Vol. 18, No.1, pp. 154-159.

[5] MARTIN V., LUMÍR H., ADAM B. (2016). Structural damping of mechanical vibration. In: Manufacturing Technology, Vol. 16, No.6, pp. 1379-1382.

[6] HOSHI, T., YOSHIMURA, M. (1974). Initial applications of dynamic structural analysis to computer-aided design of machine tools. In: Proceedings of the Fourteenth International Machine Tool Design and Research Conference. pp. 559566. Macmillan Publishers Limited, London.

[7] YOSHIMURA, M. (1975). Computer aided design of machine structures with respect to static and dynamic characteristics by synthesis of dynamic rigidity program system: Study for analysis of structural dynamics of machine tools. In: JSME International Journal, Vol. 41, No. 490, pp. 10601065.

[8] LIAO Y. Y., LIAO B. Y. (2018). Dynamic optimization design of machine tool based on modal flexibility and energy distribution. In: Journal of Mechanical Engineering, Vol. 54, No. 23, pp. 192-198.

[9] LIAO Y. Y., LIAO B. Y. (2018). Weak parts identification and design optimization for dynamic performance of milling machine performance of milling machine. In: Journal of Kunming University of Science and Technology (Natural Science), Vol. 43, No. 6, pp. 55-64.

[10] MAO K., LI B., WU J., et al. (2010). Stiffness influential factors-based dynamic modeling and its parameter identification method of fixed joints in machine tools. In: International Journal of $\mathrm{Ma}$ chine Tools \& Manufacture, Vol. 50, No. 2, pp. 156-164.

[11] ČELIČ, D., BOLTEŽAR, M. (2008). Identification of the dynamic properties of joints using frequency-response functions. In: Journal of Sound and Vibration, Vol. 317, No. 1, pp. 158174.

[12] RADEK B., MICHAL H., PAVEL P., et al. (2017). Dynamical analysis of a cable manipulator using multibody approaches. In: Manufacturing Technology, Vol. 17, No.2, pp. 152-157.

[13] STEFAN S., JAN K. (2018). The role of modelling of road unevennesses in vehicle dynamics. In: Manufacturing Technology, Vol. 18, No.1, pp. 124-129.

[14] LIAO Y. Y. (2018). Structural dynamics modeling and analysis based on Lagrange equations of energy principle. In: Journal of Interdisciplinary Mathematics, Vol. 21, No. 5, pp. 1261-1266.

[15] LI L., CAI A. J., CAI L. G. (2013). Identification method for dynamic properties of bolted joints. In: Journal of Mechanical Engineering, Vol. 49, No. 7, pp. 168-175.

[16] LIU C. Y., TAN F., WANG L. P., et al. (2016). Research on optimization of column structure design for dynamic performance of machine tool. In: Journal of Mechanical Engineering, Vol. 52, No. 3, pp. 161-168.

[17] YOSHIMURA, M. (1979). Computed-aided design improvement of machine tool structure incorporating joint dynamics data. In: Annals of the CIRP, Vol. 28, No. 1, pp. 241-246. 